\title{
Fabrication and characterization of porous hydroxyapatite ocular implant followed by an in vivo study in dogs
}

\author{
B KUNDU, M K SINHA*, M K MITRA ${ }^{\dagger}$ and D BASU \\ Oxide and Bio-Ceramic Section, Central Glass and Ceramic Research Institute, Kolkata 700 032, India \\ ${ }^{\dagger}$ Metallurgical Engineering Department, Jadavpur University, Kolkata 700 032, India
}

MS received 30 July 2003; revised 18 December 2003

\begin{abstract}
Porous hydroxyapatite ocular implant was fabricated by a novel and simple method using hydroxyapatite powder synthesized in the laboratory. The porosity and pore size of the implant were controlled to make it light in weight as well as suitable for rapid vascularization after implantation. The implant was characterized by X-ray diffraction studies, infrared spectra and chemical analysis for phase purity and chemical composition. The pore morphology and pore size distribution of the samples were investigated by scanning electron microscope (SEM). Thereafter, efficacy of the implant was examined by in vivo study in dogs. Clinical, haematological and radiological studies indicated the suitability of the implant for replacement of the lost eye of human patients.
\end{abstract}

Keywords. Bio-ceramics; hydroxyapatite; porous implant; ocular implant; in vivo study.

\section{Introduction}

Hydroxyapatite (HAp) is the principal inorganic constituent of bone and teeth. The chemical similarity of this material with bone and teeth as well as its excellent biocompatibility and bioactivity has attracted the attention of medical professionals. For the last several years, hydroxyapatite ceramics in different forms (block, granules, coating) are being used widely in the field of orthopaedics (Uchida et al 1990; Aoki 1991; Lavernia and Schoenung 1991; Ozawa and Kasugai 1996; Tampieri et al 2001; Dorozhkin and Epple 2002) and dentistry (Legeross 1988; Passi et al 1991; Ichikawa et al 1996). The extensive research on biological and physico-chemical properties of this material has widened its scope of application and in recent years it has found promising application in other areas of medicine (Aoki et al 1987; Grote 1987; Shin et al 1992) also.

The use of hydroxyapatite as an ocular implant is a relatively new development (Perry 1990, 1991; Dutton 1991; Shields et al 1991; Ferrone and Dutton 1992). When an eye of a person is damaged due to disease or injury, the surgeon removes the eyeball from the orbit to avoid the risk of life or risk to the other eye of the patient. The lost eye can be mechanically replaced by an ocular implant to fill-up the orbital volume lost after enucleation or evisceration to achieve better cosmesis and rehabilitation of the anophthalmic patient. In the past, many materials have

\footnotetext{
*Author for correspondence
}

been tried for this purpose but with little success. Until the 19th century, artificial eyes were made of metal, which were soon discarded as they were expensive, heavy and painful to wear. In 1884, Mules (1885) was the first to introduce hollow glass sphere as an implant. This sphere offered some support for the upper eyelid but was unable to relieve the chronic downward pressure on the lower lid which is essential to alleviate the lid sag characteristic of long term anophthalmic patients and therefore, the search was on for more suitable material. Subsequently numerous materials like gold, cartilage, xenogeneic animal eyes, silver, aluminium, silicone and glass beads were used to fill irregular cavities in the orbit. Most of the implants composed of these materials were found unsuitable due to various reasons and were discarded one after another. In 1941, an acrylic based, partially exposed orbital implant was introduced by Ruedemann (1946). Since this implant had to be manufactured before each operation and further secondary strabismus procedures were often required to correct late position problems, this implant was also eventually abandoned. There have been many variations in the designs of orbital implants (Gougelmann 1976) after the Ruedemann eye. The partially exposed implants imparted good motility to the artificial eye, but were prone to infection and extrusion. Buried implants were then developed (Gougelmann 1976) to provide motility through special contours on the anterior aspect of the implant which matched corresponding contours on the posterior aspect of the eye.

In recent years, porous ocular implants composed of hydroxyapatite (HAp) are widely accepted for recon- 
struction of the artificial eyes after enucleation and evisceration surgery. Porous implants capable of sustaining fibrovascular growth are termed as integrated implants. Porous implants have the advantage of becoming infiltrated by fibrovascular tissue, thereby providing resistance to infection, migration and extrusion (Rosen 1991; Shields et al 1993; Christmas et al 1998).

Currently available coralline derived HAp implants (Dutton 1991) provide excellent fibrovascular in-growth. But, these implants have a rough outer surface that sometimes abrades the overlying conjunctiva and Tenon's capsule resulting in exposure of the implant. The porosity and pore size of such implants cannot be modified and so they need to be wrapped with donor sclera or fascia lata to overcome this problem. There are also concerns about human immunodeficiency virus (HIV) infection and the need for an additional surgery to harvest a donor sclera. The availability of the starting material i.e. coral, from commercial sources is irregular and the chemical composition of the coral varies widely due to the presence of ions such as magnesium, sodium, chloride and fluoride in seawater. This affects the sintering parameters and the biological response and thereby, the control of process parameters becomes difficult. So, the need for an ocular implant material with a smoother implant surface is a necessity to reduce abrasion on the orbital tissues during and after implantation. The smoother surface is expected to facilitate deeper placement of the implant in the orbit and reduce intra-operative time because the implant may not need to be surrounded by an additional coating. In a very recent publication, Munoz et al (2001) have reported the preparation of eyeball prosthesis from HAp ceramic powder by gel-casting method. The pore size distribution of the prosthesis was in the range of $10-40 \mu \mathrm{m}$.

The objective of the present study is to provide a novel and simple process for the production of porous ocular implants from synthetic calcium hydroxyapatite and to examine its efficacy by an in vivo study in dogs.

\section{Experimental}

\subsection{Powder preparation}

The HAp powder was prepared by precipitation between $\mathrm{Ca}(\mathrm{OH})_{2}$ and $\mathrm{H}_{3} \mathrm{PO}_{4}$ according to the following reaction:

$$
10 \mathrm{Ca}(\mathrm{OH})_{2}+6 \mathrm{H}_{3} \mathrm{PO}_{4}=\mathrm{Ca}_{10}\left(\mathrm{PO}_{4}\right)_{6}(\mathrm{OH})_{2}+18 \mathrm{H}_{2} \mathrm{O} \text {. }
$$

An aqueous solution of $\mathrm{H}_{3} \mathrm{PO}_{4}$ was added very slowly to a suspension of $\mathrm{Ca}(\mathrm{OH})_{2}$. During reaction, temperature of the suspension was maintained at $80^{\circ} \mathrm{C}$ and $\mathrm{pH} 11-12$. The resulting precipitate was aged, dried and calcined at $800^{\circ} \mathrm{C}$. The calcined powder was ground in a planetary mill and characterized for phase purity, chemical composition and particle size analysis. The details of powder synthesis and its characterization have been described elsewhere (Sinha et al 2000), which is also schematically shown in figure 1.

\subsection{Fabrication of ocular implants}

The HAp powder calcined at $800^{\circ} \mathrm{C}$ was used for the fabrication of implant. The powder was intimately mixed with appropriate quantity of naphthalene powder $(300 \mu \mathrm{m}$ size $)$ by repeated sieving. The powder mix was inserted into rubber bag and compacted at a pressure of $160 \mathrm{MPa}$ by cold-isostatic pressing (EPSI NV; SO 10036, Belgium) to form cylindrical shape (diameter $25 \mathrm{~mm}$ and length $115 \mathrm{~mm}$ ) which was subsequently machined to fabricate the ocular implant. By heating at $80^{\circ} \mathrm{C}$, the naphthalene was driven off from the green implant and great care was taken at this stage to prevent cracking. Finally, the implant was sintered at $1250^{\circ} \mathrm{C}$ for $3 \mathrm{~h}$ to improve the mechanical properties. Figure 2 schematically outlines the method for fabrication of ocular implant.

\subsection{Implant characterization}

The implant was characterized by X-ray diffraction (Philips PW1710) using monochromatic $\mathrm{Cu} \mathrm{K}_{\alpha 1}$ radiation at

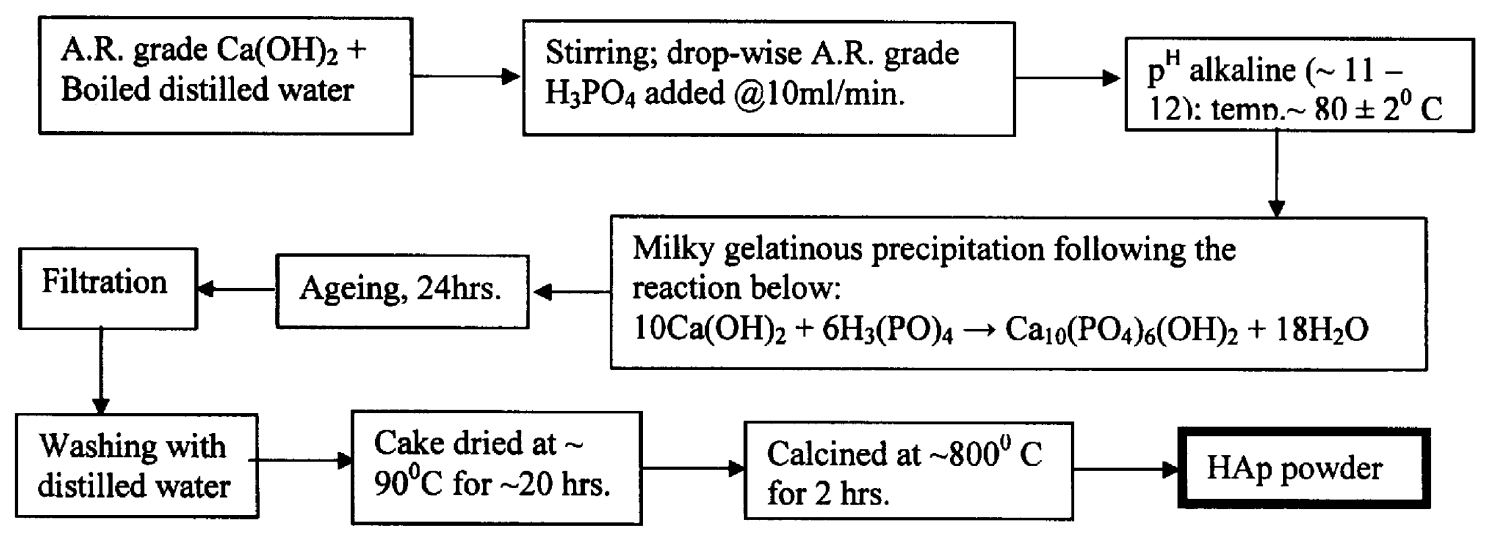

Figure 1. Scheme of the HAp powder preparation. 
$55 \mathrm{~mA}$ and $40 \mathrm{kV}$. The infrared spectrum of the sample was recorded in the $400-4000 \mathrm{~cm}^{-1}$ range by an Fourier transformed infrared spectrometer (Perkin-Elmer, Model: 1615) in the transmission mode, chemical analysis of the implant was performed by an inductively coupled plasma atomic emission spectra (Spectro Flame Modula, SpectroAnalytical Instruments, Germany, Model: STM 08). The sample was first dissolved in $\mathrm{HNO}_{3}$ and the ICP-AES analysis was then performed on the solution. Characterization of the implant with respect to phase purity and chemical composition was done mainly to compare these characteristics of the final product to that of the starting material. Bulk density and porosity were measured using

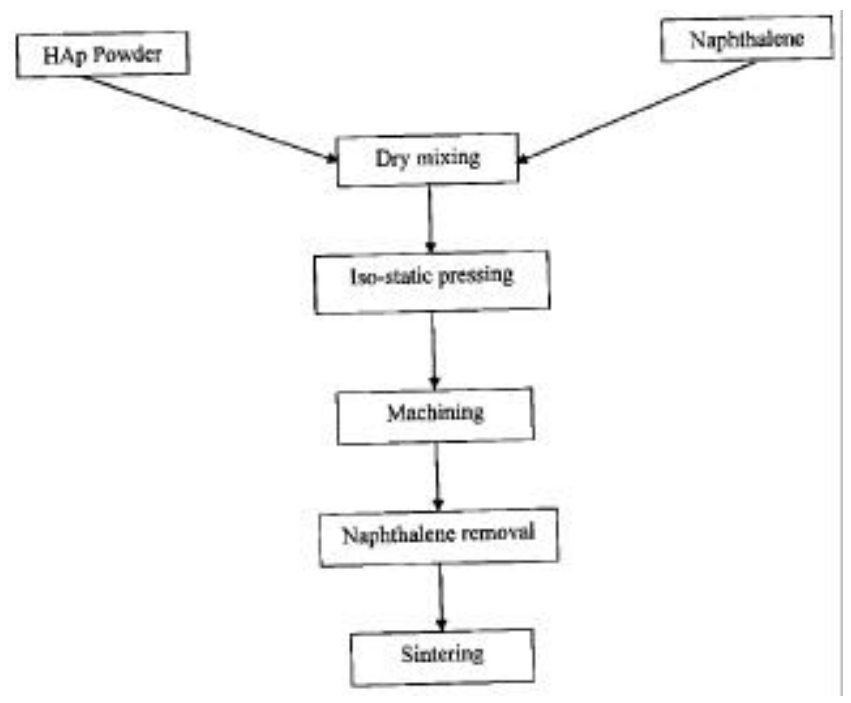

Figure 2. Schematic diagram of the fabrication method. the water displacement method i.e. by Archimedes' principle. The pore morphology and pore size distribution of the samples were investigated by SEM (LEO 430 STEROSCAN, UK). Prior to SEM analysis, the samples were ultrasonically cleaned in acetone for about $1 \mathrm{~min}$ and then the infrared dried samples were sputter coated with gold for 3 min to get a coating thickness of $\sim 50 \mathrm{~nm}$. Lineal analysis of the SEM micrograph was used to measure the pore size (Kingery et al 1976). Compressive strength was measured by Instron made universal testing machine (Model: 5500 R 1185, UK) while for determination of wear factor, a pin-on-disc machine (Ducom, Bangalore, Model: TR 20LE) was employed under $1 \mathrm{~kg}$ load and a sliding speed of $30 \mathrm{~m} / \mathrm{min}$.

\subsection{In vivo study in dog}

Six healthy adult male mongrel dogs were used in this experiment. Prior to surgery the dogs were observed closely for 3 weeks in order to check their health status and treated accordingly for internal and external parasitic infestation and other body deficits. They were maintained under identical environment, management and standard diet with ad libitum supply of drinking water. Care and management of experimental animals were followed by the guidelines issued by the Indian National Science Academy (2000), approved by the Institutional Animal Ethics Committee (IAEC) and Committee for the Purpose of Control and Supervision of Experiments on Animals (CPCSEA). Routine examinations with regard to temperature, pulse and respiration were made. Besides, routine haematological and biochemical tests were also conducted to checkup the health status. The left eyes were selected for the

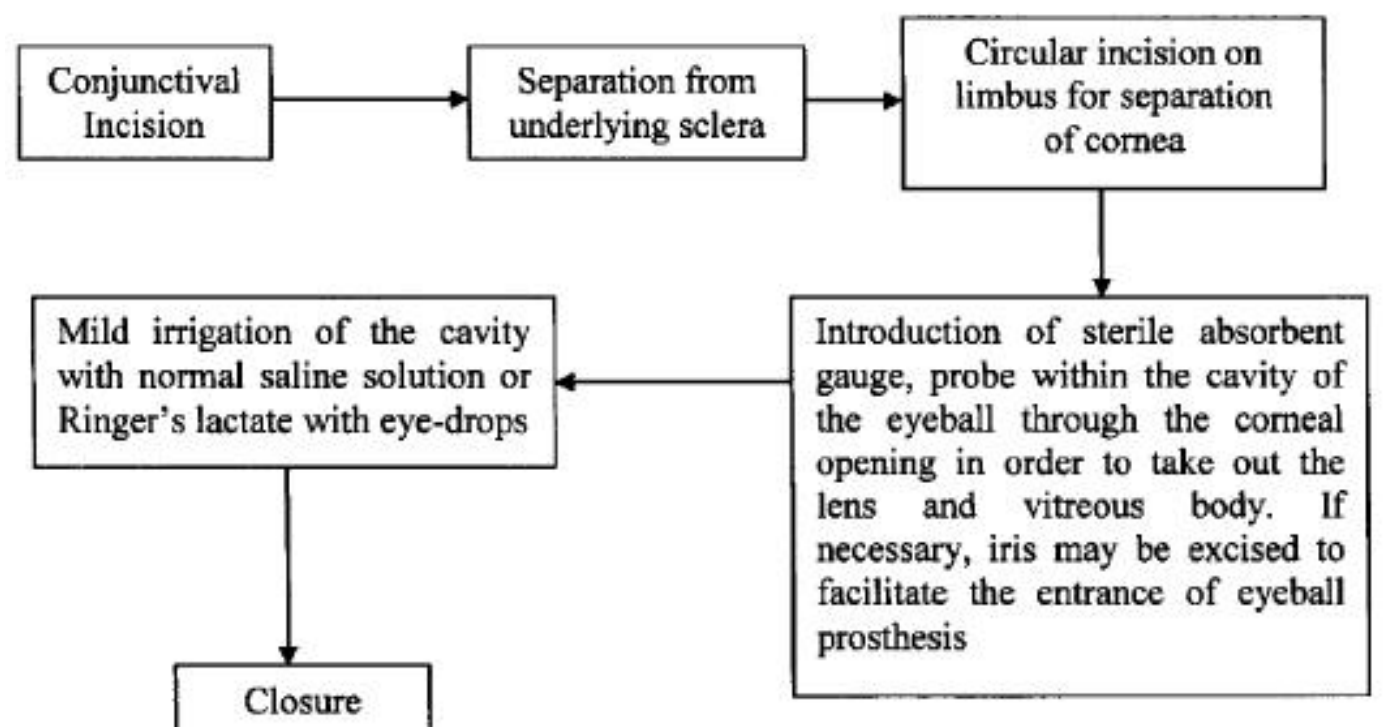

Figure 3. Schematic diagram of the operation procedure. 
surgical implantation, whereas the contra-lateral right eyes served as the control. Before the operation, implants were $\gamma$-ray sterilized with $\mathrm{Co}_{60}$ isotope of dosage $2.5 \mathrm{Mrad}$, prior to the sterilization in an autoclave. Operative procedure was basically an evisceration operation and the scheme of the surgery has been shown in figure 3 . The dogs were maintained for observation up to 90 post-operative days and strict hygienic measures were taken to combat infections in the surroundings. The operated eyes were flushed daily with normal saline solution and chloromycetin eye-applicaps. Thereafter, sofracort eye drop was given in both eyes. Eyelid suture was removed on 3rd day post-operatively. The radiological study was performed 90 days after the surgical implantation.

\section{Results and discussion}

\subsection{Porous ocular implant}

XRD pattern and IR spectrum of the implant, as shown in figures 4 and 5 , respectively were exactly similar to that of the starting material (Sinha et al 2000) indicating no change in phase composition during sintering. The $\mathrm{CaO}$ and $\mathrm{P}_{2} \mathrm{O}_{5}$ contents $\left(\mathrm{CaO}-55.54\right.$ mass\%, $\mathrm{P}_{2} \mathrm{O}_{5}-41.49$ mass\%), remained practically unchanged (Sinha et al 2000), within the experimental error, throughout the whole process of fabrication. The median particle size of HAp powder used for implant fabrication was $0.47 \mu \mathrm{m}$ (figure 6). The physical and mechanical properties of the ocular implant/ specimen have been shown in table 1. Compared to the theoretical density $(3 \cdot 16 \mathrm{~g} / \mathrm{cc})$ of HAp, the bulk density of the implant was $0.61 \mathrm{~g} / \mathrm{cc}$ and this lower value was

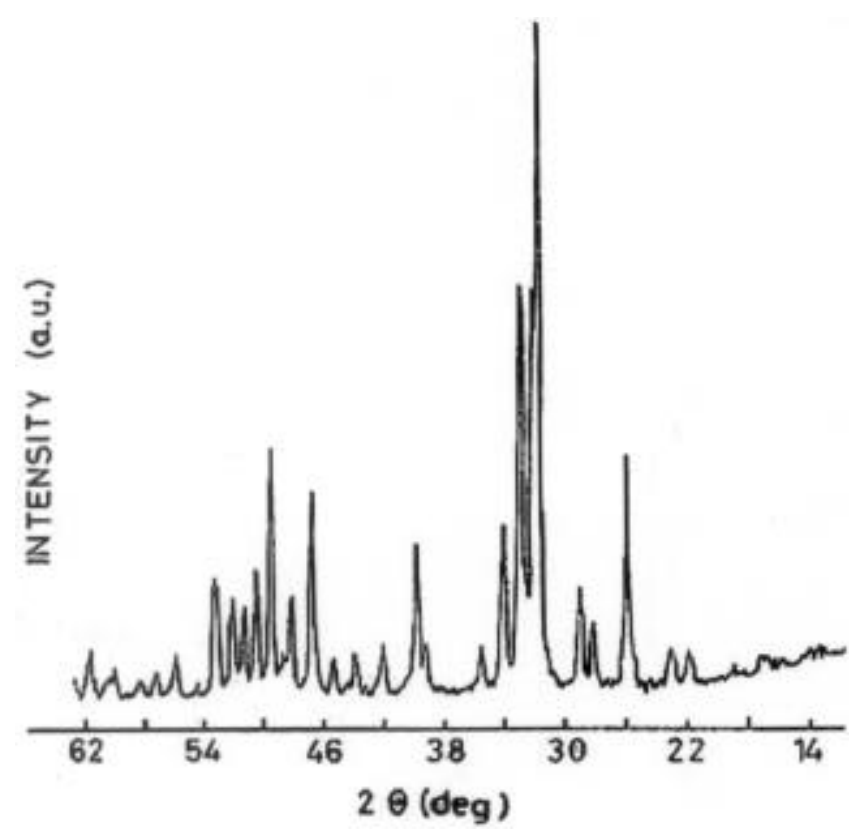

Figure 4. XRD pattern of HAp powder of the ocular implant. attributed to the higher porosity (75\%) of the implant as determined by Archimedes' method. This amount of porosity was deliberately generated in the implant in order to make it light in weight as well as to facilitate rapid vascularization. In fact the weight of implant was kept within $2 \mathrm{~g}$ to avoid the post-operative complications.

The SEM micrograph in figure 7 shows the pore morphology of the sintered HAp samples. The typical pore diameter in the porous HAp samples has a value in the range of 100-250 $\mu \mathrm{m}$ according to lineal analysis (Kingery et al 1976). Except a few closed pores, majority of the open pores were interconnected. The sintered HAp samples, whose microstructure is shown in figure 7 , has a compressive strength of $10 \pm 0 \cdot 30 \mathrm{MPa}$. The wear factor of the samples was found to be $1.2 \times 10^{-10} \mathrm{~cm}^{2} / \mathrm{g}$. The relatively low wear rate is expected to minimize the abrasion of the overlying conjunctiva and Tenon's capsule following surgery and thereby preventing the tissue breakdown over the rough anterior surface of the implant. Thus the implant could be used without the donor sclera and chances of infection from donor tissue could be reduced, since some patients refuse to accept an implant coated with allogeneic sclera due to even a theoretical risk of virus transmission such as HIV (Dutton 1991). Figure 8 shows the actual shape of hydroxyapatite ocular implant after sintering. This implant was used for in vivo study in dogs.

\subsection{In vivo evaluation}

After the surgery, at the initial phase of healing, one of the dogs exhibited some degree of lacrimation, mild conjunctivitis and serosanguinous discharge up to 3rd and 7th post-operative days, which were safely controlled by proper medication and resolution took place within the 12th post-operative day (figures 9 a-d). It was observed that the rectal temperature, pulse rate and respiration rate in the pre-operative and post-operative stages of the animals

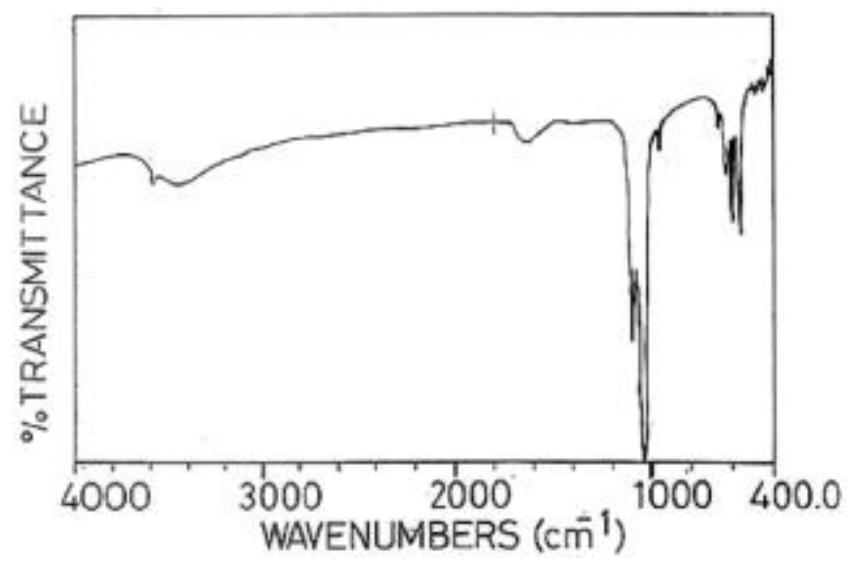

Figure 5. IR spectrum of the HAp powder of the ocular implant. 


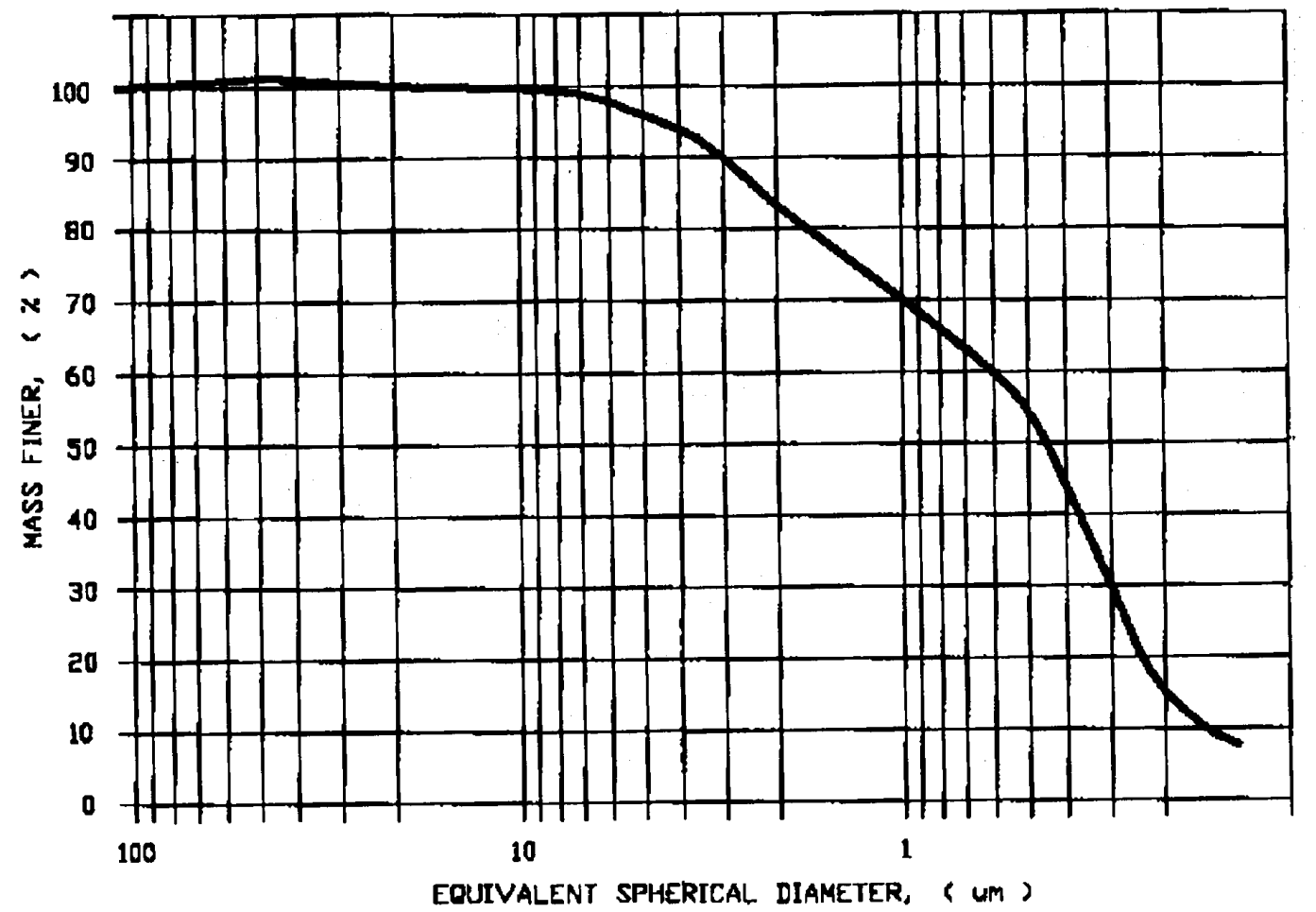

Figure 6. Particle size distribution of the calcined HAp powder.

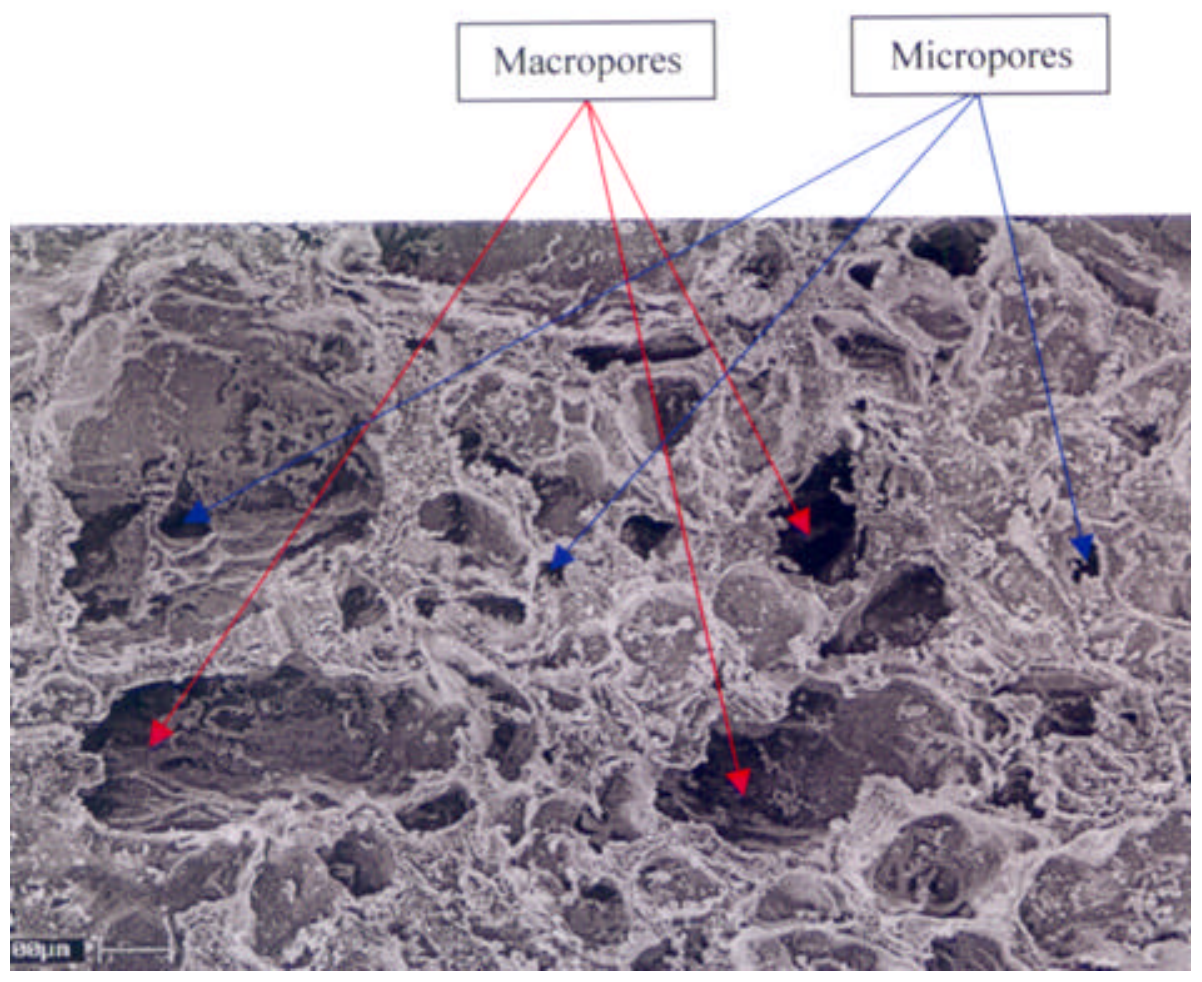

Figure 7. Scanning electron micrograph of the ocular implant (secondary electron mode with magnification, $\times 101)$. 
did not show any marked changes. The physiological status of the animals did not vary much beyond its normal physiological limits. In all the cases, the haematological results before and after operation showed only mild inflammatory changes. A comparison of the pre- and posthaematological parameters in one of the experimental canine is represented in table 2. Biochemical studies (table 3) revealed that though there was not much change in the

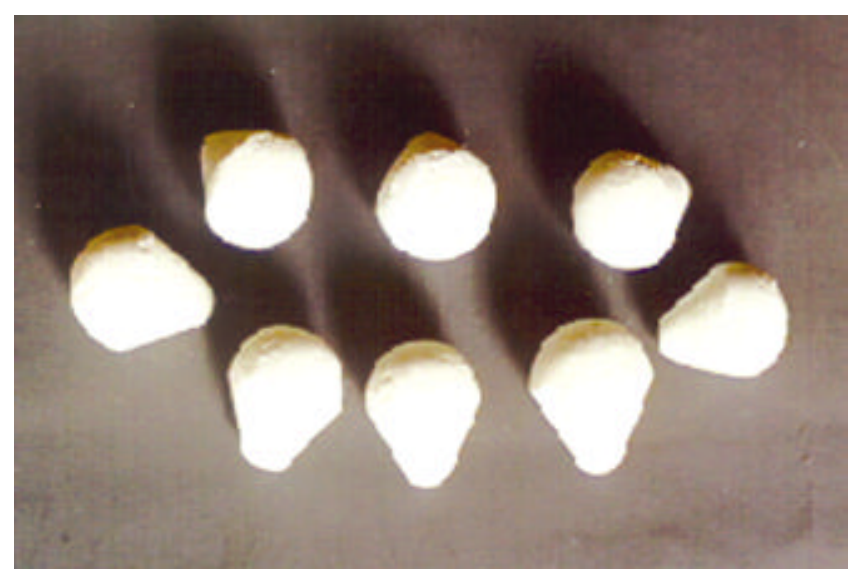

Figure 8. The porous hydroxyapatite ocular prostheses.
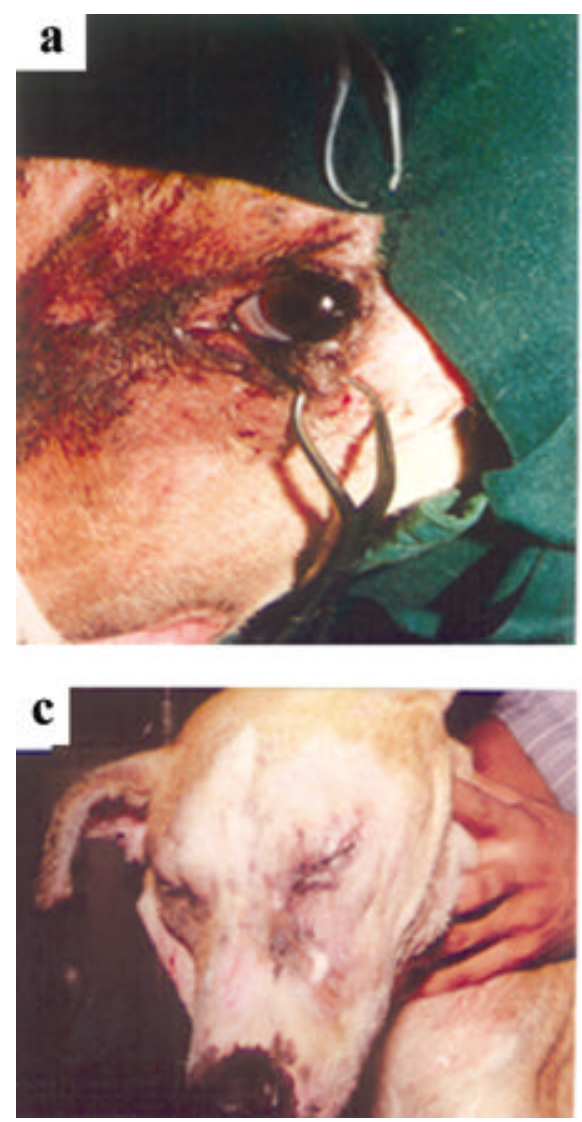

Figure 9. Photographs of the mongrel dog taken after the surgery a. during the operation, b. on the 3rd day, c. on the 7 th day and d. on the 12 th day.
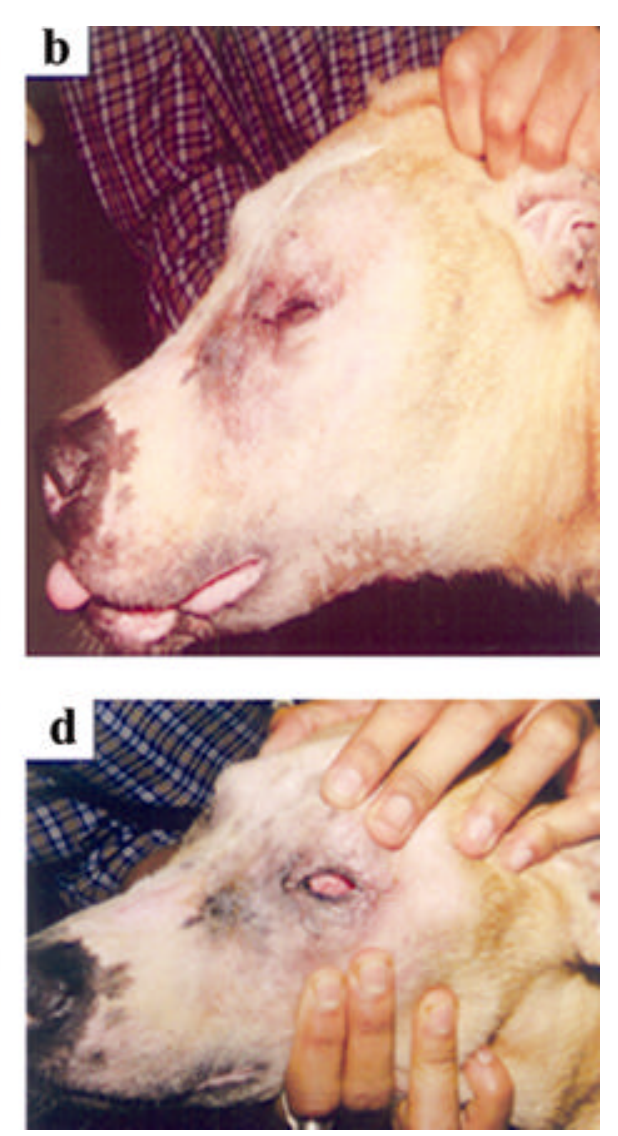

total serum protein content before and after the operation, the albumin content increased significantly in the post operative period. This suggested some degree of stress following injury and surgery. The radiological study on the animals (figure 10) showed that the prostheses were well tolerated by the surrounding tissues after the evisceration surgery. It offered excellent cosmetic reconstruction with lower rates of infection and extrusion. It maintained natural lid shape due to the light weight of the prosthesis, which minimized pressure on the lower lid. It offered excellent mobility of the socket and had satisfactory mobility of the prosthesis.

Table 1. Physical and mechanical properties of implant/ specimen.

\begin{tabular}{lc}
\hline Properties & Values \\
\hline Theoretical density & $3 \cdot 16 \mathrm{~g} / \mathrm{cc}$ \\
Bulk density & $0 \cdot 61 \mathrm{~g} / \mathrm{cc}$ \\
Total weight & $2 \mathrm{~g}$ \\
Porosity & $75 \%$ \\
Pore size & $100-250 \mu \mathrm{m}$ \\
Compressive strength & $10 \pm 0 \cdot 3 \mathrm{MPa}$ \\
Wear factor under $10 \mathrm{~N}$ load and & $1 \cdot 2 \times 10^{-10} \mathrm{~cm}^{2} / \mathrm{g}$ \\
$\quad$ sliding speed of $30 \mathrm{~m} / \mathrm{min}$ & \\
\hline
\end{tabular}


Table 2. Comparative study of haematological parameters before and after implantation of hydroxyapatite based ocular implant in canine.

\begin{tabular}{lccccc}
\hline & & \multicolumn{4}{c}{ Post-operative } \\
\cline { 3 - 6 } Parameters & Pre-operative & 0 day & 3rd day & 5th day & 7th day \\
\hline Haemoglobin $(\mathrm{g} / \mathrm{dl})$ & $11 \cdot 5$ & $11 \cdot 2$ & $11 \cdot 5$ & $12 \cdot 0$ & $12 \cdot 5$ \\
White blood corpuscles $\left(\mathrm{mm}^{3}\right)$ & 8080 & 7200 & 7800 & 7800 & 8000 \\
Red blood corpuscles $\left(\mathrm{million}^{3} \mathrm{~mm}^{3}\right)$ & $5 \cdot 80$ & $5 \cdot 60$ & $5 \cdot 70$ & $6 \cdot 0$ & $6 \cdot 10$ \\
Neutrophil $(\%)$ & $62 \cdot 8$ & $62 \cdot 2$ & $62 \cdot 0$ & $62 \cdot 4$ & $62 \cdot 0$ \\
Lymphocyte $(\%)$ & 28 & 27 & 26 & 26 & 26 \\
Eosinophil $(\%)$ & $0 \cdot 2$ & $0 \cdot 2$ & $0 \cdot 2$ & $0 \cdot 2$ & $0 \cdot 2$ \\
Monocyte $(\%)$ & 3 & 2 & 2 & 2 & 2 \\
Basophil $(\%)$ & 0 & 0 & 0 & 0 & 0 \\
\hline
\end{tabular}

Table 3. Comparative study of biochemical parameters before and after implantation of hydroxyapatite based ocular implant in canine.

\begin{tabular}{lccccc}
\hline & & \multicolumn{4}{c}{ Post-operative } \\
\cline { 3 - 6 } Parameters & Pre-operative & 0 day & 3rd day & 5th day & 7th day \\
\hline Albumin $(\mathrm{g} / \mathrm{dl})$ & $2 \cdot 6$ & $3 \cdot 4$ & $3 \cdot 2$ & $3 \cdot 0$ & $3 \cdot 2$ \\
Globulin $(\mathrm{g} / \mathrm{dl})$ & $3 \cdot 4$ & $3 \cdot 0$ & $3 \cdot 2$ & $3 \cdot 2$ & $3 \cdot 0$ \\
Total serum protein $(\mathrm{g} / \mathrm{dl})$ & $6 \cdot 0$ & $6 \cdot 4$ & $6 \cdot 4$ & $6 \cdot 2$ & $6 \cdot 2$ \\
\hline
\end{tabular}

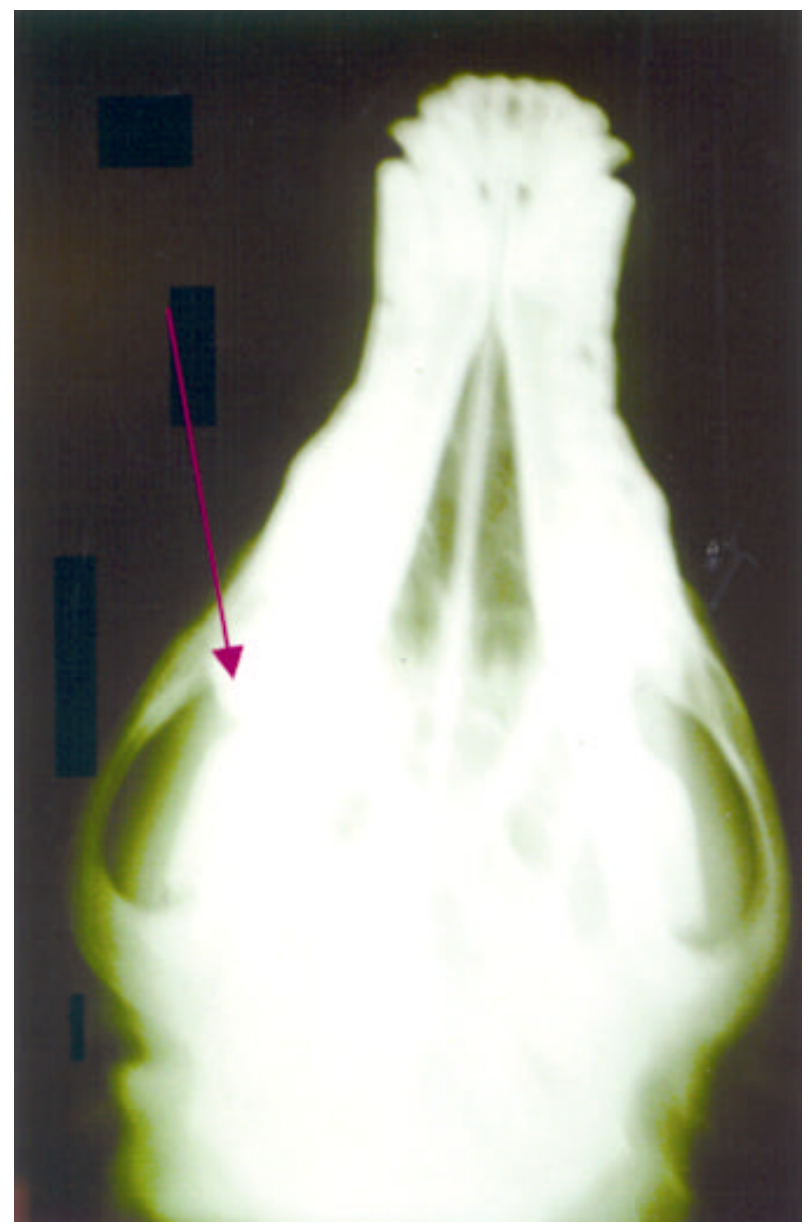

Figure 10. Radiography of the canine implantation site.

\section{Conclusions}

The fabrication of tailor-made ocular implant is not possible with coralline derived calcium hydroxyapatite. So the problem of non-availability of coral in bulk amount from commercial source for large-scale production has been overcome in this method as the raw materials used for synthesis of medical grade HAp are commercially available in large quantity for mass production.

The ocular implant with tailor made properties with respect to total mass, porosity, pore size and surface roughness fabricated by this novel and simple method in this study, is therefore economical and suitable for industrial production.

The in vivo study in dogs has revealed that the implant was well tolerated without showing extrusion and infection. It allowed the recipient blood vessels and fibrous tissues to grow into the implant, thus becoming a living portion of the orbital tissues and once vascularized, it is less likely to migrate or to extrude. Finally, it is concluded from the experimental results that porous synthetic hydroxyapatite ocular implant can be conveniently used in human beings to replace the lost eye.

\section{Acknowledgements}

Thanks are due to Prof R Mukherji, Director, Eye Care and Research Centre, Kolkata and Dr S Mitra, Senior Surgeon, Eye Care and Research Centre, Kolkata, for discussion and invaluable suggestions. The authors also thank 
Dr P K Samanta, and Dr P Jha, Department of Surgery and Radiology, West Bengal University of Animal and Fishery Sciences, Kolkata, for conducting implantation studies on the Mongrel dogs. Thanks are also due to Mr P S Sen, Mr J Chakraborty, Mr L K Naskar, Mr D K Naskar for their technical support, Dr Mondal, Saha Institute of Nuclear Physics, Kolkata, for conducting $\gamma$-ray sterilization of the prostheses and Society of Bio-Medical Technology, Defence Research and Development Organisation, Ministry of Defence, Government of India, for their financial support towards this work.

\section{References}

Aoki H 1991 in Science and medical applications of hydroxyapatite (Japan: JAAS Press)

Aoki H et al 1987 Medical Progress through Technology 12213

Christmas N J et al 1998 Arch. Ophthalmol. 1161199

Dorozhkin S V and Epple M 2002 Angew. Chem. Int. Ed. 41 3130

Dutton J J 1991 Ophthalmology 98370

Ferrone P J and Dutton J J 1992 Ophthalmology 99376

Gougelmann H P 1976 Int. Ophthalmol. Clin. 10689

Grote J J 1987 Am. J. Otol. 8396
Ichikawa T, Hirota K and Kanitani H 1996 J. Oral. Implantol. 22232

Kingery W D, Bowen H K and Uhlmann D R 1976 in Introduction to ceramics (New York: Wiley) p. 526

Lavernia C and Schoenung J M 1991 Am. Ceram. Bull. 7095

Legeross R Z 1988 Adv. Dent. Res. 2164

Mules P H 1885 Trans. Ophthalmol. Soc. UK 5200

Munoz E R, Diaz J R, Rodriguez J R, Brostow W and Castano V M 2001 J. Mats. Sc.: Mats. Med. 12305

Ozawa S and Kasugai S 1996 Biomaterials 1723

Passi V, Marin T W, Miotti A and Pareti A 1991 in Ceramics in substitutive and reconstructive surgery (ed.) $\mathrm{P}$ Vincenzini (San Diego, USA: Elsevier Science Publication) p. 467

Perry A C 1990 Adv. Ophthalmic Plast. Reconstr. Surg. 875

Perry A C 1991 Ophthalmol. Clin. North Am. 4173

Rosen H M 1991 Plast. Reconstr. Surg. 881076

Ruedemann A D 1946 Am. J. Ophthalmol. 29947

Shields C L, Shields J A, Eagle R C and de Potter P 1991 Am. J. Ophthalmol. 111363

Shields C L et al 1993 Trans. Am. Ophthalmol. Soc. 91177

Shin Y et al 1992 J. Mats. Sc.: Mats. Med. 3219

Sinha M K, Basu D and Sen P S 2000 Interceram 2102

Tampieri A, Celotti G, Sprio S, Delcogliano A and Franzese S 2001 Biomaterials 221365

Uchida A, Araki N, Shinto Y, Yorshkawa H, Kurisaki E and Ono K 1990 J. Bone Joint Surg. (Br.) B72 298 